means of supply) and the savings made through the lower generating costs claimed for PWRs. This shift in government policy will be seized upon by the objectors, who this week include the Campaign for Nuclear Disarmament and the Stop Sizewell B Association.

The stress on diversity will be used by environmentalist to persuade the inspector that CEGB has given insufficient attention to the potential of renewable energy sources such as wave and wind power. The lower generating costs claimed for PWRs are also likely to be challenged, since CEGB's economic case appears to rely on future increases in the cost of coal. A recent CEGB study has revealed that so far electricity generated from nuclear power in the United Kingdom has been more expensive than electricity from coal.

The Nuclear Installations Inspectorate (NII) will take the stand in April to start their evidence on safety aspects of the pro- posed design. It is clear that NII will not have completed its examination of CEGB's design by this time: on 1 March it detailed 80 outstanding issues on which it is seeking more information from CEGB. The inspector may consider an adjournment to enable NII to extend its presentation. NII has denied responsibility for delays in providing information on safety issues and blames CEGB for failing to provide NII with its Pre-Construction Safety Report until 10 months after the scheduled date. NII says "there can be no short cuts in carrying out the licensing process, and progress will depend on the timing and quality of the material provided"

It is to be hoped that Sir Frank Layfield has a hardy constitution: the inquiry is already expected to last at least until the end of the year. He is not unfamiliar with the subject, however, having represented some of the objectors at the Windscale inquiry in 1977.
Journal of Physics and other leading journals to be published in Russian, and they call on the respective editors to insist that no such excisions are made as a condition of agreeing to such an arrangement.

This last point illustrates the vacuum in which the refusniks live - Nature, for example, has heard nothing of such a project. Nor do the refusniks realize that while many scientists are prepared to visit the unofficial seminars as private individuals, it may not be possible for them professionally to have their names openly linked with them. The question of publication of refusniks' articles - as many participants in the scientists' colloquium reiterated - is a very painful one; much as they would like to help, the information lag almost inevitably means that the articles are outdated before they ever reach a Western editor's desk.

With exit visas for Jews down to a dozen or so a week, heavy policy pressure on refusnik seminars and increased pressure on those Jewish academics serving sentences in labour camp or exile, the participants in the scientists' seminar decided to set up an international coordinating secretariat to synchronize and render more telling protests by the scientific community.

In one respect, however, their efforts will no longer be needed. During the past two years, at least ten Jewish scientists have been deprived of their higher degrees for exhibiting an insufficient degree of Soviet patriotism. This practice, the refusniks say, has now ceased - the authorities have abandoned it as a tactical error, apparently as a result of Western condemnation.

Vera Rich discuss the worsening situation of Jewish scholars and scientists in the Soviet Union, whether or not they wish to emigrate.

Those concerned request in particular that all help tendered should be on the basis of their status as scientists, not as charity. Their statement says that invitations to foreign scientific conferences can be of particular help. Although an exit visa for the term of the conference will almost certainly be refused, such invitations serve as reminders to the authorities and may even lead to a reassessment of their status. The statement also asks that scientists invited to the Soviet Union should use the opportunity to get in touch with refusniks and that distinguished foreign scientists should put pressure on the Soviet Academy of Sciences. Scientists from international bodies such as CERN, the European centre for nuclear physics, with which the Soviet Union wishes to maintain good relations, may be especially influential.

Other suggestions in the statement are: - Foreign scientists should attend the unofficial seminars organized by the refusniks, thus helping to avoid police interference.

- Western scientists are asked to help refusniks to get their papers published, particularly in seeing papers through the publication process.

- Refusniks need scientific journals, as they are excluded from academic libraries; in

the case of those sentenced to Siberian exile, the refusniks' journals should be sent to next of kin. journals should deal with the refusniks? plight, pointing out that articles dealing with the subject are omitted from the photocopied versions circulated by the central library service in the Soviet Union. They have heard, however, that negotiations are soon to begin for cover-to-covertranslations of Nature, Science, American

\section{Acting ambassadors}

Scientists and scholars tend to be regarded by the Soviet authorities as unofficial ambassadors for the Soviet system. For this reason they prefer to send to an international conference some staid and elderly personage who can be trusted to behave with decorum, rather than some brilliant young researcher who might come out with an indiscreet criticism of the Soviet Union.

This tacitly understood role for the Soviet scientist was more clearly defined recently by Academician Georgiy Skryabin, a principal academic secretary of the Soviet Academy of Sciences. Addressing the annual general meeting of the academy this month he praised the "great work" done by scientists abroad at conferences and study trips in "explaining the resolutions of the twenty-sixth party congress, and the internal and external policy of the Soviet Union'.

The main public relations service the scientists have performed, Dr Skryabin noted, related to Soviet proposals for peace and security. They had spoken up in international forums against the threat of nuclear catastrophe.

Nothing was said at this meeting, however, of the possibility (widely discussed in Moscow just before Brezhnev's death) of a Soviet initiative to form a Soviet version of an international organization of scientists against nuclear war parallel to the existing doctors' organization. Indeed, Academician E. P. Velikhov, who had been widely tipped to head the putative organization, and who recently gave a major interview on the dangers of nuclear war on Moscow television, confined his remarks at the meeting to the importance of organizing the academy's research on automation and computer science. The peace issue was well to the fore, though, with the awarding of the 1982 Lomonosov medals, the highest award of the academy, presented annually to one Soviet and one foreign scientist. This year, the foreign recipient was Professor Dorothy Hodgkin of the University of Oxford, whose campaigning for peace was especially commended by Academician Yuriy $\mathbf{A}$. Ovchinnikov in his keynote speech "Marxism and Scientific-Technological Progress".

Vera Rich 